\section{The Psychopharmacology of Schizophrenia}

Edited by Michael A. Reveley \& J. F.William Deakin. London: Arnold. 1999. 269 pp.

£45.00 (hb). ISBN 0340759127

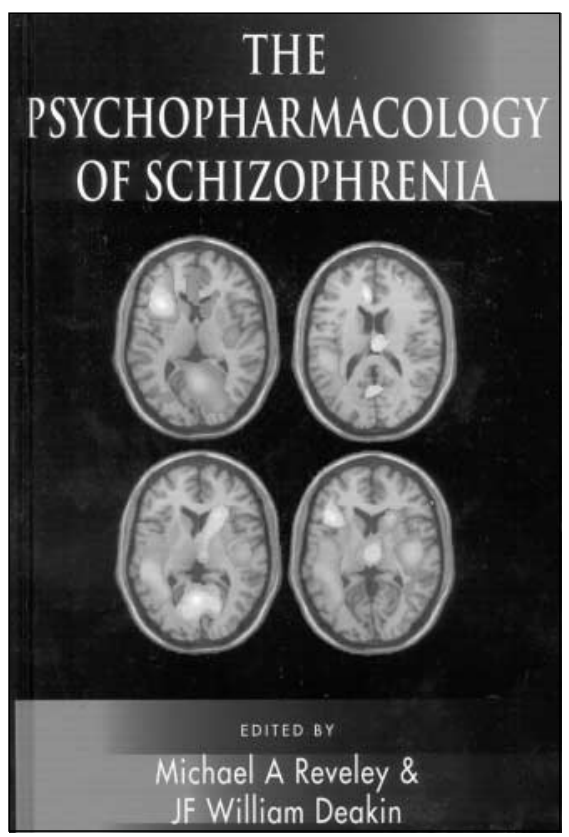

This multi-authored text provides a concise, yet comprehensive, overview of many of the advances made in the biological research of schizophrenia over recent years. It contains chapters that, at first glance, may not appear to be relevant to a psychopharmacologist, for example, the neuropsychology of schizophrenia, structural and functional brain imaging, and the molecular genetics of schizophrenia. However, the patience of the diligent, systematic reader is rewarded by insights gained into the potential for antipsychotics to modify cognition, the correlates of neuroimaging and treatment responses, inherent methodological shortcomings in functional imaging techniques, and an awareness of the capacity of $\mathrm{D}_{2}$ receptor antagonists to modulate the activity of mRNA.

Most of the authors are clinicians. This is reflected in the style of presentation, which tends to focus on practical treatment options, rather than impenetrable lists of letters and numbers representing drugs at various stages of development. The editors have successfully coordinated thinking between contributors throughout the volume. Accordingly, there is relatively little contradictory material, and differences in transatlantic practice are appropriately flagged.

This book will appeal to a range of postgraduate readers. At one level, it provides explanations of terms for those seeking to expand their knowledge of biological psychosis research. Phencyclidine and ketamine models of psychoses, genetic imprinting, anticipation and positional cloning, the BOLD effect, T2* and signal : noise ratio are all lucidly explained. On another level, several chapters tackle gritty issues of interest to contemporary schizophrenia researchers, such as an accessible explanation of the complexities of radiotracer kinetics in positron emission tomography (PET) and single photon emission tomography (SPET) studies, and another explores the enigmatic relationship between $5-\mathrm{HT}_{2}$ receptors and antipsychotic efficacy.

The high price of this hardback book will deter non-academics and trainees from purchasing it. However, it should be allocated space in the psychiatry library, where it is likely to be in demand over the next few years.

Gillian A. Doody Clinical Senior Lecturer in General Adult Psychiatry, University of Nottingham, Division of Psychiatry, Duncan MacMillan House, Porchester Road, Nottingham NG6 3AA

\section{The Image of Madness: The Public Facing Mental IIIness and Psychiatric Treatment}

Edited by J. Guimón,W. Fischer \& N. Sartorius. Basel: Karger. 1999. US\$128.75 (hb)

ISBN 3805545460

The theme of this book is the public's perception, often stigmatising, of mental illnesses and the impact this can have on compliance with pharmacological methods of treatment. This is considered in relation to strategies for tackling stigmatisation and related discrimination against medical interventions in particular. The hand of the pharmaceutical industry is obvious but, although this has influenced the book's orientation, there is also much of a general nature to appreciate. The book has a strong Swiss base, in the form of authorship of 10 of the 22 chapters.

Several substantial studies of the social representations of mental illnesses in the public mind and also among health care professionals are reported. For psychiatrists, often accused of detrimentally labelling those with mental distress, it is interesting to be reminded that pigeon-holing and labelling deviant groups is a universal proclivity. The public's crude categorisation is into the 'seriously mad' and the 'less seriously distressed'. Criteria are behavioural, with emphasis on violence. Only under such circumstances is the intervention of psychiatrists welcomed. The public's perception of schizophrenia, predictably, is found yet again to be akin to the psychiatric concept of multiple personality disorder. The blame for this should be laid squarely on Bleuler and his redefinition of the core features and mechanisms within the syndrome, thereafter misconstrued and avidly taken up by society at large. Overall, the text makes little attempt to challenge the public's crude categorisation of those with mental illness, focusing as it does almost exclusively on schizophrenia. Authors have little doubt that it is the most stigmatised of the mental illnesses, whereas the Royal College of Psychiatrists' own survey of public opinions of the wide range of mental illnesses shows that people with drug or alcohol addiction are most negatively perceived. The doubtless even more seriously stigmatised group of people with antisocial personality disorder is also not considered here.

There are early interesting chapters on the metaphorical status of schizophrenia in particular and the methodological problems and profound weaknesses of much 'attitude research'. The reader is reminded that responses to survey-type questions concerning alleged attitudes but exclusively within the cognitive domain can be far removed from affective reactions and related behaviours. Correspondingly, exclusively educational efforts to change attitudes are revealed as sterile, at least in the short term. Contact with and supervised personal experience of people with mental illnesses is slightly more effective, especially - but still only moderately so - among health care workers such as medical and nursing students in systematic clinical programmes. There is a good medico-political statement by Sartorius in this section of the book, with reference to the World Psychiatric Association's global campaign to combat stigmatisation of people with schizophrenia and the strategies and instruments being developed for that purpose.

Two-fifths of the book is given over to studies concerning non-compliance, largely in relation to neuroleptic medication. Chronicity, lack of insight, search for autonomy, fear of addiction, fear by both the patient and the family of labelling and ever greater discrimination are among the 